$5-15-2002$

\title{
Investigation of The Magnetic Properties in Strontium-Borate Vanadate Glasses
}

Manford Chinkhota

Wayne State University

Petru S. Fodor

Cleveland State University, p.fodor@csuohio.edu

G. D. Khattak

King Fahd University of Petroleum \& Minerals

Lowell E. Wenger

Wayne State University, wenger@physics.wayne.edu

Follow this and additional works at: https://engagedscholarship.csuohio.edu/sciphysics_facpub

Part of the Physics Commons

How does access to this work benefit you? Let us know!

Publisher's Statement

(C) 2002 American Institute of Physics.

\section{Repository Citation}

Chinkhota, Manford; Fodor, Petru S.; Khattak, G. D.; and Wenger, Lowell E., "Investigation of The Magnetic Properties in Strontium-Borate Vanadate Glasses" (2002). Physics Faculty Publications. 203.

https://engagedscholarship.csuohio.edu/sciphysics_facpub/203

This Article is brought to you for free and open access by the Physics Department at EngagedScholarship@CSU. It has been accepted for inclusion in Physics Faculty Publications by an authorized administrator of

EngagedScholarship@CSU. For more information, please contact library.es@csuohio.edu. 
Investigation of the magnetic properties in strontium-borate vanadate glasses

Manford Chinkhota and Petru S. FodorG. D. KhattakL. E. Wenger

Citation: 91, 8269 (2002); doi: 10.1063/1.1456438

View online: http://dx.doi.org/10.1063/1.1456438

View Table of Contents: http://aip.scitation.org/toc/jap/91/10

Published by the American Institute of Physics 


\section{Investigation of the magnetic properties in strontium-borate vanadate glasses}

Manford Chinkhota and Petru S. Fodor

Department of Physics, Wayne State University, Detroit, Michigan 48201

G. D. Khattak

Department of Physics, King Fahd University of Petroleum \& Minerals, Dhahran-31261, Saudi Arabia

L. E. Wenger ${ }^{\text {a) }}$

Department of Physics, Wayne State University, Detroit, Michigan 48201

To further elucidate the nature of the valence state of $\mathrm{V}$ ions in vanadate glasses, magnetic susceptibility measurements in the temperature range of 5 to $300 \mathrm{~K}$ have been performed on a series of vanadium-strontium-borate $\left(\mathrm{V}_{2} \mathrm{O}_{5}+\mathrm{SrO}+\mathrm{B}_{2} \mathrm{O}_{3}\right)$ oxide glasses with $\mathrm{V}_{2} \mathrm{O}_{5}$ concentrations greater than $50 \mathrm{~mol} \%$. The magnetic susceptibility for these oxide glasses is found to consist of a temperature-independent paramagnetic contribution arising from $\mathrm{V}_{2} \mathrm{O}_{5}$ and a Curie-Weiss temperature-dependent contribution associated with magnetic $\mathrm{V}^{4+}$ ions being present in concentrations between $2 \%$ and $10 \%$ of the total V concentration. The negative Curie-Weiss temperatures in the range of 0 to $-2.8 \mathrm{~K}$ indicate a weak antiferromagnetic interaction between the $\mathrm{V}^{4+}$ ions. These results are consistent with a glass network structure consisting of $\mathrm{VO}_{5}$ polyhedra in which the $\mathrm{V}^{4+}$ would be predominantly isolated species, and any interactions between the $\mathrm{V}^{4+}$ ions would result from superexchange interactions through $\mathrm{V}-\mathrm{O}-\mathrm{V}$ bonds. (C) 2002 American Institute of Physics. [DOI: 10.1063/1.1456438]

\section{INTRODUCTION}

Studies on oxide glasses containing transition-metal (TM) ions continue to be of interest due to their semiconducting properties that arise from the hopping of unpaired electron(s) between TM ions having two different valence states. ${ }^{1-4}$ Since vanadium can exist in several different oxidation states (e.g., $\mathrm{V}^{5+}$ and $\mathrm{V}^{4+}$ ), these vanadate glasses can exhibit electrical (semiconducting) and magnetic (superparamagnetic) properties ${ }^{5}$ that are of particular technological importance. The present work extends previous studies on the magnetic properties of vanadate glasses ${ }^{6-9}$ by investigating the magnetic properties on a series of $\mathrm{V}_{2} \mathrm{O}_{5}-\mathrm{SrO}-\mathrm{B}_{2} \mathrm{O}_{3}$ glass samples. Magnetic susceptibility $(\chi)$ measurements in combination with inductively coupled plasma spectroscopy (ICP) have been used to determine the ratio of different valence states of the $\mathrm{V}$ ions in these glasses. In addition, the possibility exists for magnetic interactions between the conjugate ions $\mathrm{V}^{4+}\left(3 d^{1}\right)$. The extent and nature of this interaction can correspondingly be deduced from parameters associated with the observed Curie-Weiss behavior $[\chi$ $=C /(T-\theta)]$ of these glasses.

\section{EXPERIMENT}

\section{A. Glass preparation}

The glasses were prepared by melting dry mixtures of reagent grade $\mathrm{V}_{2} \mathrm{O}_{5}, \mathrm{SrO}$, and $\mathrm{B}_{2} \mathrm{O}_{3}$ in alumina crucibles with various batch compositions as shown in Table I. Approximately $30 \mathrm{~g}$ of chemicals were thoroughly mixed to obtain homogenized batches. The crucible containing the

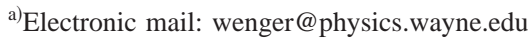

batch mixture was placed in a furnace, heated at $300^{\circ} \mathrm{C}$ for 1 $\mathrm{h}$ and then transferred to an electrically heated melting furnace maintained at $1100{ }^{\circ} \mathrm{C}$. The melt was left for about 3.5 $\mathrm{h}$ under atmospheric conditions in the furnace during which the melt was occasionally stirred with an alumina rod. The homogenized melt was then cast onto a stainless steel plate mold to form glass buttons from which smaller pieces were cut for magnetic measurements. The actual compositions of the glasses were determined by ICP and are listed in Table I.

\section{B. Magnetization measurements}

The temperature-dependent dc magnetic susceptibility was measured using a Quantum Design SQUID magnetometer (model MPMS-5S) in a magnetic field of 5000 Oe over a temperature range of 5 to $300 \mathrm{~K}$. The susceptibility of the sample holder is negligible below $100 \mathrm{~K}$ for all samples, with less than a $2 \%$ correction at the highest temperature for all samples. The overall accuracy of the magnetic measurements is estimated to be approximately $3 \%$ due to the uncertainty of the magnetometer calibration.

\section{RESULTS AND DISCUSSION}

The magnetic susceptibility results for a series of $\left(\mathrm{V}_{2} \mathrm{O}_{5}\right)_{x}(\mathrm{SrO})_{1-x}$ glass samples where $x=0.8,0.7$, and 0.6 are displayed in Fig. 1 as plots of the inverse magnetic susceptibility, $H / M$, as a function of the temperature, $T$. The susceptibility data do not appear to follow a simple CurieWeiss behavior $[M / H=C /(T-\theta)]$ as there is a distinct downward curvation in the data over the entire temperature range. After attempting several other fitting possibilities, it was found that the data for each sample could be fitted to a positive temperature-independent constant plus the Curie- 
TABLE I. Compositions and magnetic characterization parameters for the vanadate glasses.

\begin{tabular}{|c|c|c|c|c|c|c|c|c|}
\hline \multirow[b]{2}{*}{ Composition } & \multirow[b]{2}{*}{ Batch } & \multicolumn{3}{|c|}{ Actual } & \multirow{2}{*}{$\begin{array}{r}(M / H)_{\text {const }} \\
\left(\frac{10^{-7} \mathrm{emu}}{\mathrm{g} \mathrm{Oe}}\right)\end{array}$} & \multirow{2}{*}{$\begin{array}{c}C \\
\left(\frac{10^{-4} \mathrm{emu} \mathrm{K}}{\mathrm{g} \mathrm{Oe}}\right)\end{array}$} & \multirow{2}{*}{$\begin{array}{c}\theta \\
(\mathrm{K})\end{array}$} & \multirow[b]{2}{*}{$\mathrm{V}^{4+} / \mathrm{V}$} \\
\hline & & $\mathrm{V}_{2} \mathrm{O}_{5}$ & $\mathrm{SrO}$ & $\mathrm{B}_{2} \mathrm{O}_{3}$ & & & & \\
\hline \multirow[t]{3}{*}{$\left(\mathrm{V}_{2} \mathrm{O}_{5}\right)_{x}(\mathrm{SrO})_{1-x}$} & $x=0.6$ & 0.591 & 0.409 & - & 1.17 & 0.700 & 0.03 & 0.0236 \\
\hline & $x=0.7$ & 0.692 & 0.308 & - & 1.55 & 0.955 & -0.05 & 0.0289 \\
\hline & $x=0.8$ & 0.792 & 0.208 & - & 2.00 & 1.54 & -2.85 & 0.0427 \\
\hline \multirow[t]{3}{*}{$\left(\mathrm{V}_{2} \mathrm{O}_{5}\right)_{0.5}(\mathrm{SrO})_{0.5-y}\left(\mathrm{~B}_{2} \mathrm{O}_{3}\right)_{y}$} & $y=0.1$ & 0.498 & 0.415 & 0.087 & 0.670 & 0.603 & -0.07 & 0.0225 \\
\hline & $y=0.2$ & 0.483 & 0.299 & 0.218 & 0.630 & 0.731 & 0.42 & 0.0270 \\
\hline & $y=0.3$ & 0.516 & 0.214 & 0.270 & 0.850 & 1.41 & -1.38 & 0.0489 \\
\hline \multirow[t]{4}{*}{$\left(\mathrm{V}_{2} \mathrm{O}_{5}\right)_{x}(\mathrm{SrO})_{0.2}\left(\mathrm{~B}_{2} \mathrm{O}_{3}\right)_{0.8-x}$} & $x=0.5$ & 0.516 & 0.214 & 0.270 & 0.850 & 1.41 & -1.38 & 0.0489 \\
\hline & $x=0.6$ & 0.613 & 0.209 & 0.178 & 2.00 & 3.24 & -2.64 & 0.1007 \\
\hline & $x=0.7$ & 0.701 & 0.209 & 0.091 & 1.67 & 2.47 & -1.94 & 0.0721 \\
\hline & $x=0.8$ & 0.792 & 0.208 & 0.000 & 2.00 & 1.54 & -2.85 & 0.0427 \\
\hline
\end{tabular}

Weiss temperature-dependent term. The temperatureindependent constants are determined from a hightemperature extrapolation of $M / H$-versus- $1 / T$ plots for temperatures above $200 \mathrm{~K}$. After subtracting these temperature-independent constants from the measured susceptibility data, the resulting $M^{*} / H\left(=M / H-(M / H)_{\text {const }}\right)$ data follow a Curie-Weiss behavior as demonstrated in Fig. 2. The magnetic susceptibility data for the other two series of glasses, $\left(\mathrm{V}_{2} \mathrm{O}_{5}\right)_{0.5}(\mathrm{SrO})_{0.5-y}\left(\mathrm{~B}_{2} \mathrm{O}_{3}\right)_{y}$ and $\left(\mathrm{V}_{2} \mathrm{O}_{5}\right)_{x}(\mathrm{SrO})_{0.2}\left(\mathrm{~B}_{2} \mathrm{O}_{3}\right)_{0.8-x}$, also show a similar behavior and were fitted to a temperature-independent term plus the temperature-dependent Curie-Weiss contribution following an analogous procedure. The temperature dependence of the resulting inverse susceptibility, $H / M^{*}$, after subtracting out the constants for the other two series of vanadate glasses are shown in Figs. 3 and 4 . The resulting parameters$(\mathrm{M} / \mathrm{H})_{\text {const }}$, the Curie constant $\mathrm{C}$, and the paramagnetic $\mathrm{Cu}-$ rie temperature $\theta$-obtained from this fitting procedure are listed in Table I for all samples. Note that the magnitude of the temperature-independent term, $(M / H)_{\text {const }}$, is about one order of magnitude smaller than the Curie-Weiss contribution at room temperature.

A temperature-independent contribution can be expected to be present in these oxide glasses as the $\mathrm{V}^{5+}, \mathrm{V}^{4+}, \mathrm{Sr}^{2+}$,

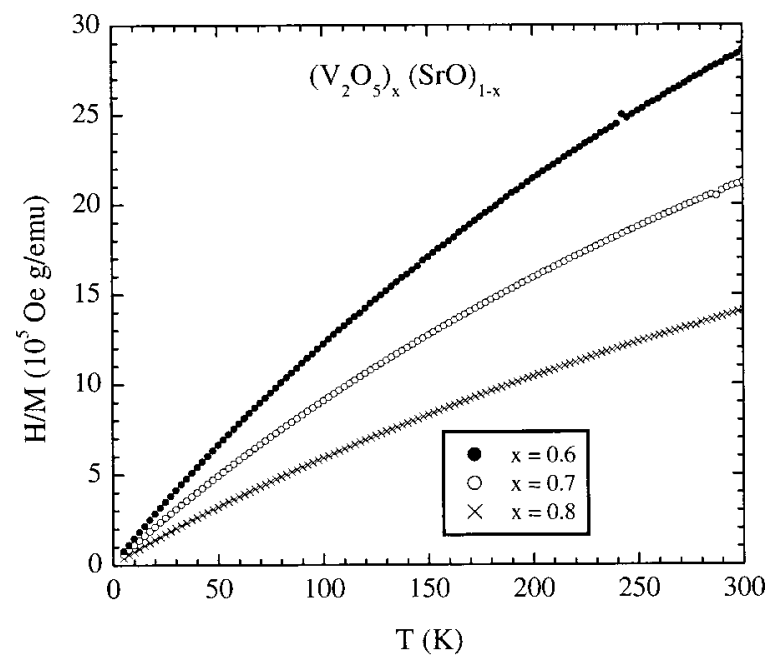

FIG. 1. The temperature dependence of the inverse magnetic susceptibility, $H / M$, for a series of $\left(\mathrm{V}_{2} \mathrm{O}_{5}\right)_{x}(\mathrm{SrO})_{1-x}$ glass samples.
$\mathrm{B}^{3+}$, and $\mathrm{O}^{2-}$ ions will give rise to a temperatureindependent diamagnetic contribution, while $\mathrm{V}_{2} \mathrm{O}_{5}$ gives a temperature-independent paramagnetic contribution on the order of $10^{-4} \mathrm{emu} / \mathrm{mol}$ Oe. ${ }^{10}$ Since this latter value is an order of magnitude larger than the typical diamagnetic contributions from the core ions, we can expect that the $\mathrm{V}_{2} \mathrm{O}_{5}$ paramagnetic contribution will dominate over the response arising from the core diamagnetism of the glass ions. This is in agreement with the experimental evidence of $(M / H)_{\text {const }}$ being positive. Furthermore, this interpretation is consistent with the $\mathrm{V}_{2} \mathrm{O}_{5}$ concentration dependence of $(\mathrm{M} / \mathrm{H})_{\text {const }}$ for the entire series of glasses. For example, $(M / H)_{\text {const }}$ for the $\left(\mathrm{V}_{2} \mathrm{O}_{5}\right)_{x}(\mathrm{SrO})_{1-x}$ glasses increases as $x$ increases while there is less variation in $(M / H)_{\text {const }}$ for the $\left(\mathrm{V}_{2} \mathrm{O}_{5}\right)_{0.5}(\mathrm{SrO})_{0.5-y}\left(\mathrm{~B}_{2} \mathrm{O}_{3}\right)_{0.5-y}$ glass series having a fixed vanadium concentration.

Since $\mathrm{V}^{5+}$ ions are nonmagnetic, the Curie-Weiss behavior observed in these glasses must be associated with a fraction of the vanadium ions being in another oxidation state, most probably $\mathrm{V}^{4+}$. X-ray photoemission spectroscopy studies $^{11}$ on identical glass samples support this hypothesis as the $\mathrm{V} 2 p$ spectra show two peaks, one associated with the presence of $\mathrm{V}^{5+}$ ions and a smaller one associated with $\mathrm{V}^{4+}$. Thus, determinations of the Curie-Weiss parameters in con-

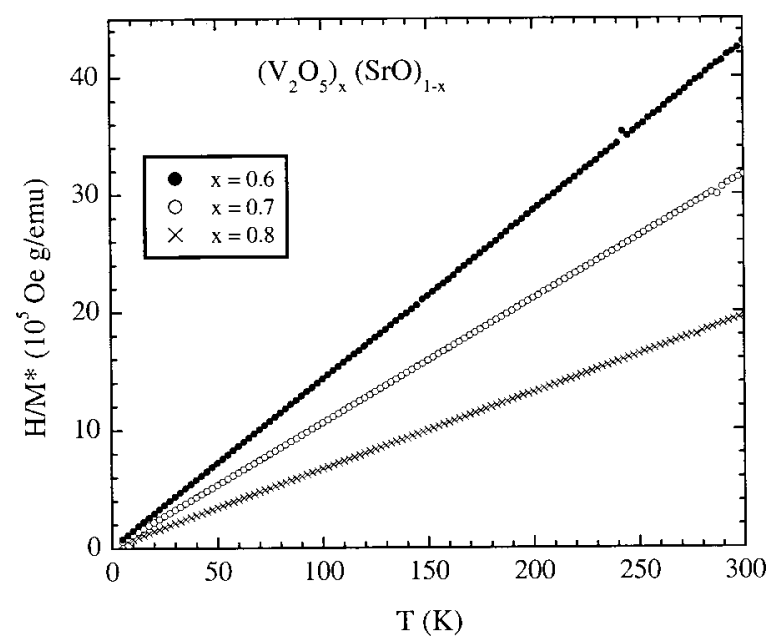

FIG. 2. The inverse magnetic susceptibility, $H / M^{*}$, for a series of $\left(\mathrm{V}_{2} \mathrm{O}_{5}\right)_{x}(\mathrm{SrO})_{1-x}$ glass samples as a function of temperature. 


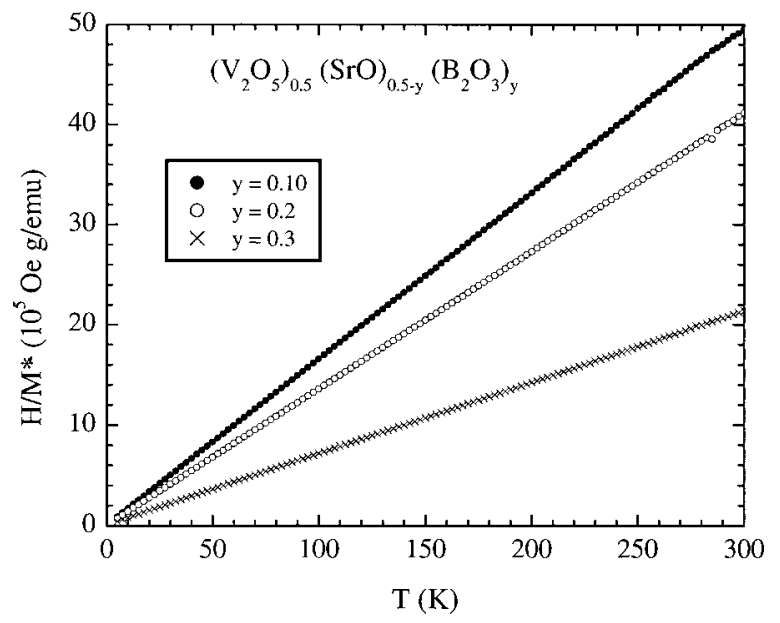

FIG. 3. The inverse magnetic susceptibility, $H / M^{*}$, for a series of $\left(\mathrm{V}_{2} \mathrm{O}_{5}\right)_{0.5}(\mathrm{SrO})_{0.5-y}\left(\mathrm{~B}_{2} \mathrm{O}_{3}\right)_{y}$ glass samples as a function of temperature.

junction with concentration determinations by chemical analysis on these oxide glasses result in magnetic $\mathrm{V}^{4+}$ ions $\left(p_{\text {eff }}=1.73 \mu_{\mathrm{B}}\right.$ ) being present in concentrations between $2 \%$ and $10 \%$ of the total $\mathrm{V}$ concentration for these glasses. These percentages are consistent with other recent results ${ }^{8}$ on strontium vanadate glasses as well as the trend for increasing $\mathrm{V}^{4+}$ concentrations with increasing $\mathrm{V}_{2} \mathrm{O}_{5}$ concentrations. As a result, one would expect the electrical conductivity to be the

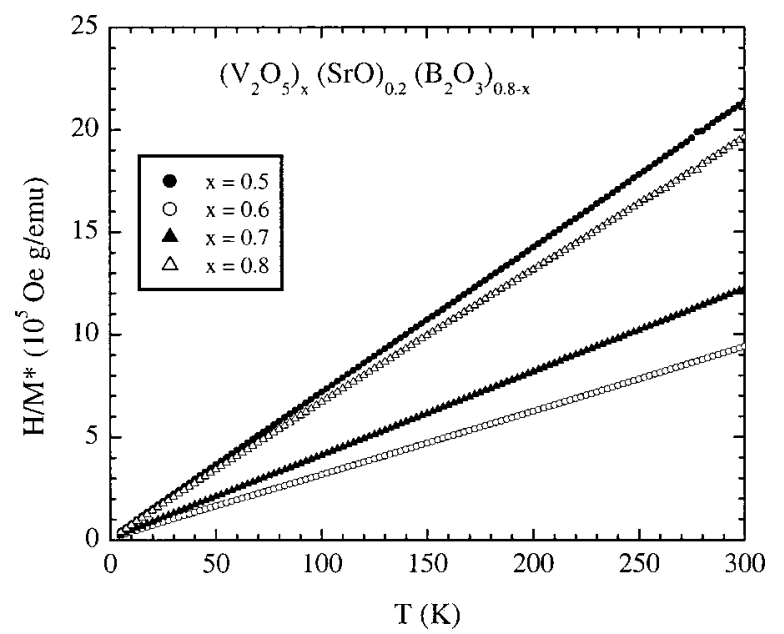

FIG. 4. The inverse magnetic susceptibility, $H / M^{*}$, for a series of $\left(\mathrm{V}_{2} \mathrm{O}_{5}\right)_{x}(\mathrm{SrO})_{0.2}\left(\mathrm{~B}_{2} \mathrm{O}_{3}\right)_{0.8-x}$ glass samples as a function of temperature. highest for the glasses having the largest $\mathrm{V}_{2} \mathrm{O}_{5}$ concentrations as the availability of unpaired $3 d^{1}$ electrons to hop from the $\mathrm{V}^{4+}$ sites to the $\mathrm{V}^{5+}$ sites would be greater.

The $\theta$ values found in the present measurements of these vanadate glasses are found to range from 0 to $-2.8 \mathrm{~K}$, indicating a weak antiferromagnetic interaction between the $\mathrm{V}^{4+}$ ions. Typically the values of $\theta$ are proportional to the strength of the interaction and the number of neighboring magnetic ions. Assuming a glass network structure consisting of mainly $\mathrm{VO}_{5}$ polyhedra, ${ }^{8}$ any interactions between the $\mathrm{V}^{4+}$ ions result from superexchange interactions through $\mathrm{V}-\mathrm{O}-\mathrm{V}$ bonds. Owing to the low content of $\mathrm{V}^{4+}$ ions in these vanadate glasses, $\mathrm{V}^{4+}$ would exist predominantly as isolated species in these concentrated vanadate glasses with a limited number of $\mathrm{V}^{4+}-\mathrm{O}-\mathrm{V}^{4+}$ bonds being present.

In conclusion, magnetic susceptibility measurements in the temperature range of 5 to $300 \mathrm{~K}$ have been performed on a series of strontium-borate-vanadate $\left(\mathrm{V}_{2} \mathrm{O}_{5}+\mathrm{SrO}\right.$ $+\mathrm{B}_{2} \mathrm{O}_{3}$ ) glasses to elucidate the nature of the valence state of the $\mathrm{V}$ ions. The magnetic susceptibility was found to consist of a temperature-independent paramagnetic contribution arising from $\mathrm{V}_{2} \mathrm{O}_{5}$ and a Curie-Weiss temperaturedependent contribution associated with magnetic $\mathrm{V}^{4+}$ ions being present in concentrations between $2 \%$ and $10 \%$ of the total $\mathrm{V}$ concentration. The negative Curie-Weiss temperature values in the range of 0 to $-2.8 \mathrm{~K}$ indicated a weak antiferromagnetic interaction between the $\mathrm{V}^{4+}$ ions.

\section{ACKNOWLEDGMENTS}

This work is supported in part by the National Science Foundation Grant No. DGE-9870720 and by the KFUPM Physics Department and Research Committee (Grant PH/ PHYSPROP/43).

${ }^{1}$ J. D. Mackenzie, Modern Aspects in the Vitreous State (Butterworth, London, 1964), Vol. 3.

${ }^{2}$ N. F. Mott, J. Non-Cryst. Solids 1, 1 (1968).

${ }^{3}$ D. Adler, in Amorphous Semiconductors (CRC, Cleveland, OH, 1971).

${ }^{4}$ I. G. Austin and E. J. Garbett, in Electronic and Structural Properties of Amorphous Semiconductors, edited by P. G. LeComber and J. Mart (Academic, London, 1973).

${ }^{5}$ D. W. Collins and L. N. Mulay, J. Am. Ceram. Soc. 54, 69 (1971).

${ }^{6}$ I. Ardelean, O. Cozar, and Gh. Ilonca, J. Non-Cryst. Solids 68, 33 (1984).

${ }^{7}$ S. Sen and A. Ghosh, J. Phys.: Condens. Matter 11, 1529 (1999).

${ }^{8}$ S. Sen and A. Ghosh, J. Mater. Res. 15, 995 (2000).

${ }^{9}$ G. D. Khattak, M. A. Salim, L. E. Wenger, and A. H. Gilani, J. Non-Cryst. Solids 262, 66 (2000).

${ }^{10}$ Y. Kawamota, J. Tanida, H. Hamada, and H. Kiriyama, J. Non-Cryst. Solids 38-39, 301 (1980).

${ }^{11}$ G. D. Khattak, M. A. Salim, and L. E. Wenger (unpublished). 